\title{
Representação gráfica de rotinas administrativas
}

1. Introduçăo. 2. A necessidade de representaça grafice de rotinas administrativas. 3. Simbolos. 4. Tipos de fluxogramas.
Este artigo objetiva a apresentação de recursos auxiliares, de uso fácil, para a representação gráfica de rotinas de trabalho em escritórios. Tal representação é feita pelo uso de símbolos e esquemas, que permitem análises de quaisquer tipos, tanto superficiais como pormenorizadas e aprofundadas.

Esses símbolos representam gràficamente as diversas operações básicas envolvidas em trabalhos administrativos, bem como os diferentes tipos de documentos nelas envolvidos. Além disso, são apresentados fluxogramas de vários tipos, tais como o fluxograma panorâmico, o de Rotinas de Trabalho e o de Operações, cuja exposição está ilustrada por exemplos práticos, que explicam a aplicação dos símbolos e a técnica para o preenchimento dos fluxogramas.

Este artigo destina-se aos técnicos em racionalização de trabalhos administrativos, analistas de sistemas, e a todos aquêles que, direta ou indiretamente, estejam envolvidos em trabalhos de racionalização ou de análise de sistemas.

\section{A NECESSIDADE DA REPRESENTAÇAO GRAFICA DE ROTINAS ADMINISTRATIVAS}

Muitas vêzes, torna-se necessário substituirmos a apresentação de uma rotina de trabalho, expressa apenas por palavras, por uma apresentação esquemática, que permita uma visualização dos eventos, e que seja racional e sistemàticamente organizada. Para tanto, torna-se necessário que, além de aumentarmos - grau de detalhamento, utilizarmos símbolos representativos das ocorrências observadas.

Em descrições dessa natureza, que se constituem em modalidades de fluxogramas, o texto é complementado pelo uso de símbolos que representam as diversas operações de trabalho, bem como os documentos nelas envolvidos. Tanto o texto como os símbolos são dispostos no esquema de acôrdo com determinadas regras, que têm como objetivo tornar a apresentação do fluxo de trabalho mais compreensível, sistemática e racional.

\section{Os fluxogramas de rotinas} administrativas são, geralmente, elaborados nos seguintes casos:

a) quando do planejamento $\mathrm{e}$ estudo geral de rotinas de trabalhos administrativos, objetivando sua racionalização e simplificação;

b) quando da análise de uma rotina já existente, com o objetivo de registro dos dados colhidos, de uma maneira clara, precisa e concisa;

* Professor de mercadologia do Instituto de Administração e Geréncia da Instituto de Administração e Gerencia Curso Intensivo de Administraçăo de Empresas da Escola Brasileira de Administracáo Pública da Fundaça Administraçăo Pab
Getulio Vargas. 
c) quando da pesquisa e análise das diversas sub-rotinas constitutivas de uma rotina de trabalho;

d) quando da apresentação e implantação de uma nova rotina de trabalho, objetivando a clareza e compreensão da mesma;

e) quando do desenvolvimento e revisão de rotinas de trabalho.

\section{SIMBOLOS}

Os símbolos usados na representação das diversas operações de trabalho, bem como dos documentos envolvidos, foram criados tendo-se em mente os seguintes pontos:

a) limitá-los ao minimo indispensável;

b) facilidade de distinção;

c) facilidade de representaçăo gráfica.

\subsection{Símbolos básicos}

Foi adotado um símbolo próprio para cada operação básica realizada em trabalhos administrativos, inclusive para aquela referente à inutilizaçăo de documentos, assim:

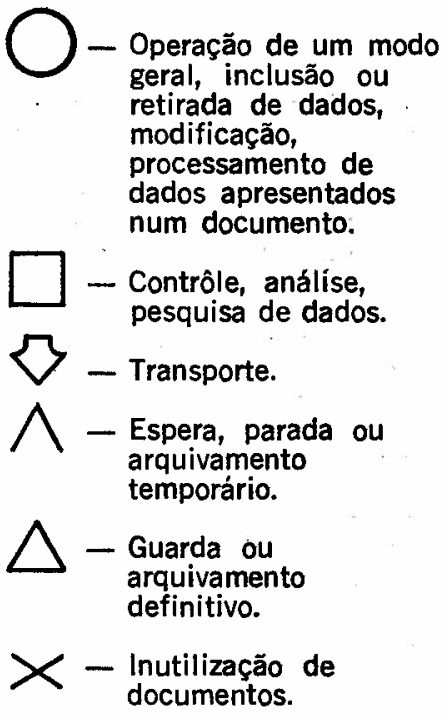

\subsection{Símbolos de documentos}

Grande parte dos trabalhos administrativos consiste no processamento de documentos; assim, na representacão gráfica de determinada rotina de trabalho toma-se necessária a utilizaçăo de símbolos que classifiquem e identifiquem cada documento em particular, e dessa forma, temos:

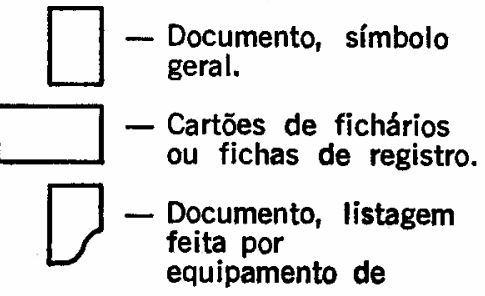

processamento de dados ou qualquer tipo de listagem.

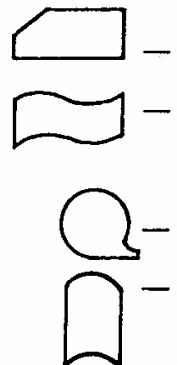

- Cartão perfurado.

- Fita perfurada ou cartões de margens perfuradas.

- Fita magnética.

- Memória de equipamento de processamento de dados - símbolo geral.

Para maior facilidade de identificação dos diversos documentos e suas respectivas vias na parte interna de cada símbolo deve-se colocar uma letra maiúscula seguida de um algarismo em ordem crescente, ou de outra forma, desde que convenientemente codificados. Todos os símbolos mencionados são encontrados no gabarito de símbolos apresentado na figura 1.

FIGURA 1. Gaberito da simbolos

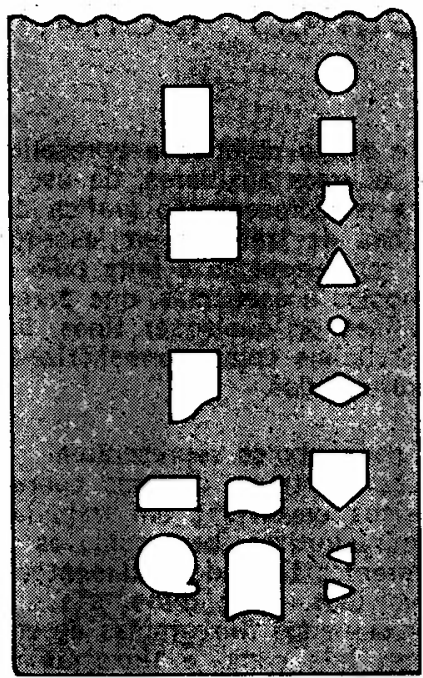

\section{TIPOS DE FLUXOGRAMAS}

A seguir passaremos a apresentar os três tipos de fluxogramas, mencionados no primeiro parágrafo dêste trabalho. Tal apresentaçāo será feita por meio de exemplos práticos, que deixarão bem claras a aplicação $e$ a técnica de utilização dos símbolos já aludidos.

\subsection{Fluxograma panorâmico}

O fluxograma panorâmico é utilizado para fins informativos, oferecendo em linhas gerais, e de modo fàcilmente compreensivel, um meio de apresentar o fluxo de documentos e o desenvolvimento do trabalho de um determinado setor.

Os documentos que ingressam no curso de um serviço são 
representados pelos seus símbolos básicos, de acôrdo com a codificação estabelecida. 0 desenvolvimento do serviço pròpriamente dito é descrito por palavras, sendo que a apresentação ainda pode ser ilustrada mediante o uso de figuras que representem os elementos-chave ou os pontos-chave da rotina. A figura 2 apresenta um exemplo de fluxograma panorâmico, no qual é mostrado o fluxo de uma rotina atual de trabalho, onde são envolvidos cinco departamentos.

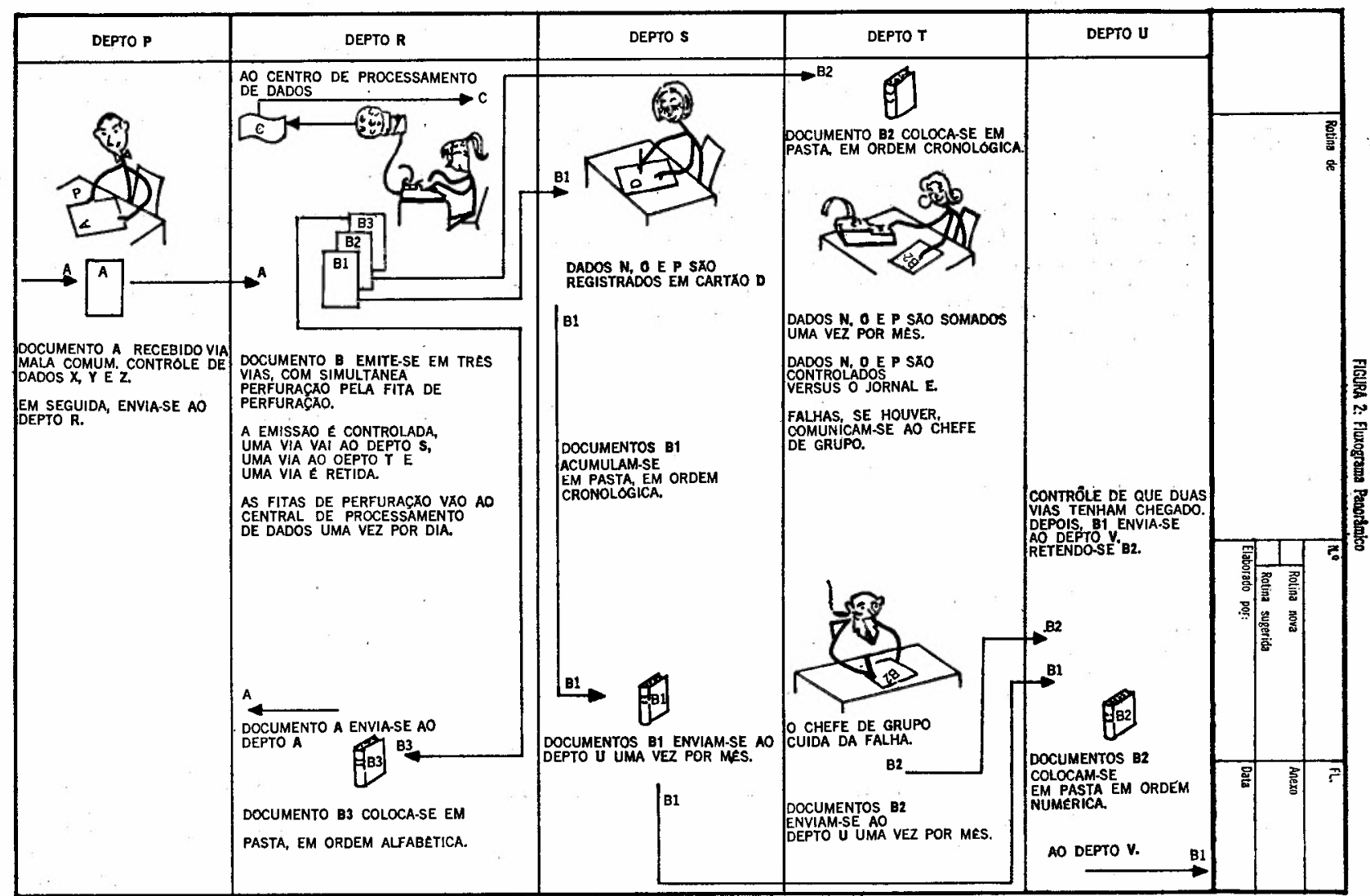

\subsection{Fluxograma de rotinas de trabalho}

Pela utilização dos fluxogramas de rotina de trabalho, é-nos possível obter descrições suficientemente claras e precisas, que servem para iluștrar a interligação entre diversas unidades de um sistema ou de uma rotina, como também a interligação entre diversas operações e, ,ainda, entre estas e os diversos

documentos nelas envolvidos. 0

nível de detalhamento do

fluxograma poderá ser adaptado de acôrdo com suas finalidades, e de acôrdo com o nível do pessoal a que se destine.

Quando da elaboração de

fluxogramas de rotinas de trabalho, utilizam-se alguns símbolos complementares, além dos símbolos básicos e de documentos, já mencionados nos itens 3.1 e 3.2. Na confecção dêsses fluxogramas, a cada símbolo seguir-se-ão breves textos, que devem proporcionar informaçōes básicas sôbre determinados aspectos, bem como sôbre os documentos afetos a uma dada operação.

Tais símbolos serão utilizados de acôrdo com as seguintes normas:

4.2.1 Normas a serem seguidas na elaboração de fluxogramas de rotinas de trabalho.

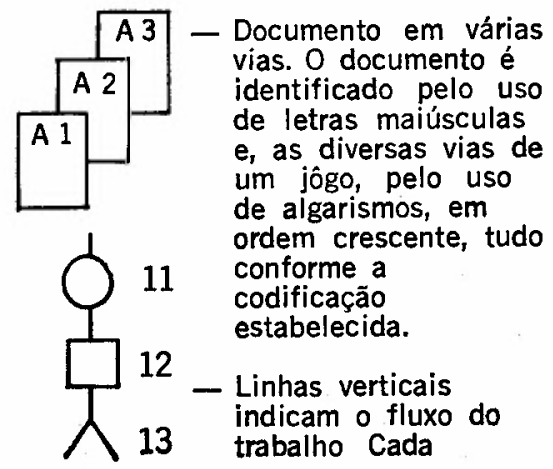

operação recebe um número de identificação para que a ela se possa fazer referências $\mathrm{e}$ comentários.

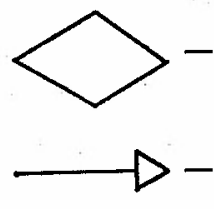

Símbolo de decisão - escolha de alternativas.

Flecha simples com haste contínua, partindo do símbolo de documento, em direção à linha de fluxo, ou símbolo de operação: indica o acréscimo de um ou mais documentos.

.......-D - Flecha simples com haste tracejada, partindo do símbolo de documento em direção à linha de fluxo, ou símbolo de operação: significa leitura ou retirada de dados do documento. 


\section{0 número da outra rotina é indicado acima da linha divisória do 1.2 .3 símbolo $e$ abaixo dessa linha, indica-se o número da fôlha do fluxograma em que se encontra a continuação: fôlha 1 , que por sua vez tem prosseguimento na fôlha 4 da mesma rotina 123 .}

\section{Exemplo 7}

Este exemplo demonstra um caso onde o fluxo de dados constitui uma continuação do fluxo apresentado na fôlha 6 , de uma mesma rotina ou sub-rotina: em cima da referência que dá inicio ao fluxo indicam-se os códigos dos documentos envolvidos no fluxo que aqui tem prosseguimento. Por sua vez, êsse fluxo também possui continuaçōes em dois novos fluxogramas de rotinas de trabalho. A continuação do fluxo de E1 será apresentada na fôlha 12 dessa mesma rotina e o fluxo de G será descrito na fôlha 1 da rotina número 10 .

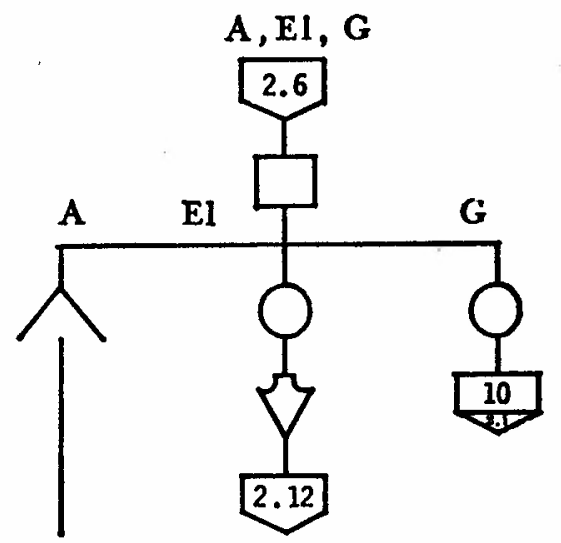

As figuras 3 e 4 apresentam um exemplo de fluxograma de rotinas de trabalho, pelo qual se pode ter uma idéia mais real de como fica a apresentação final de uma rotina.

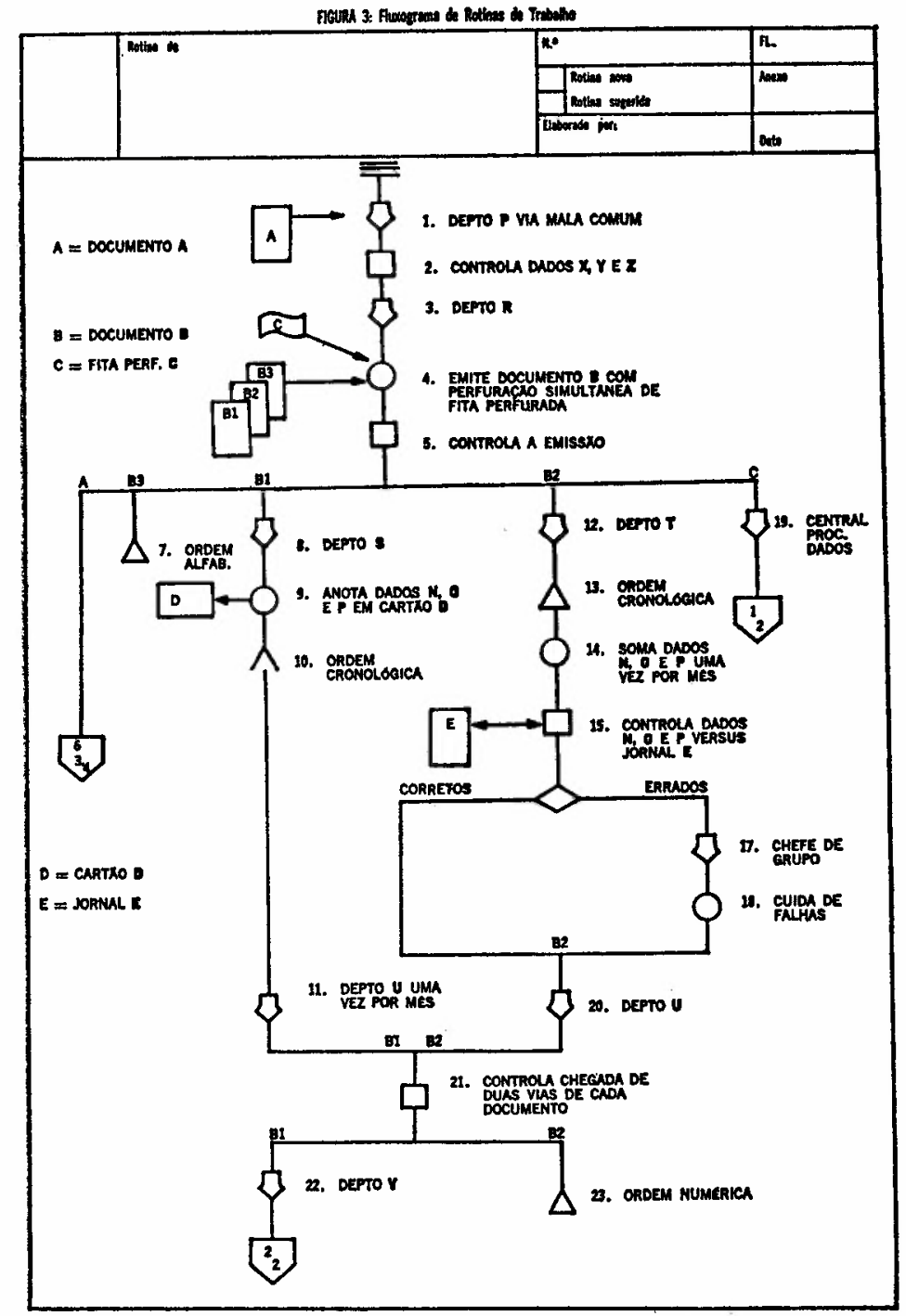




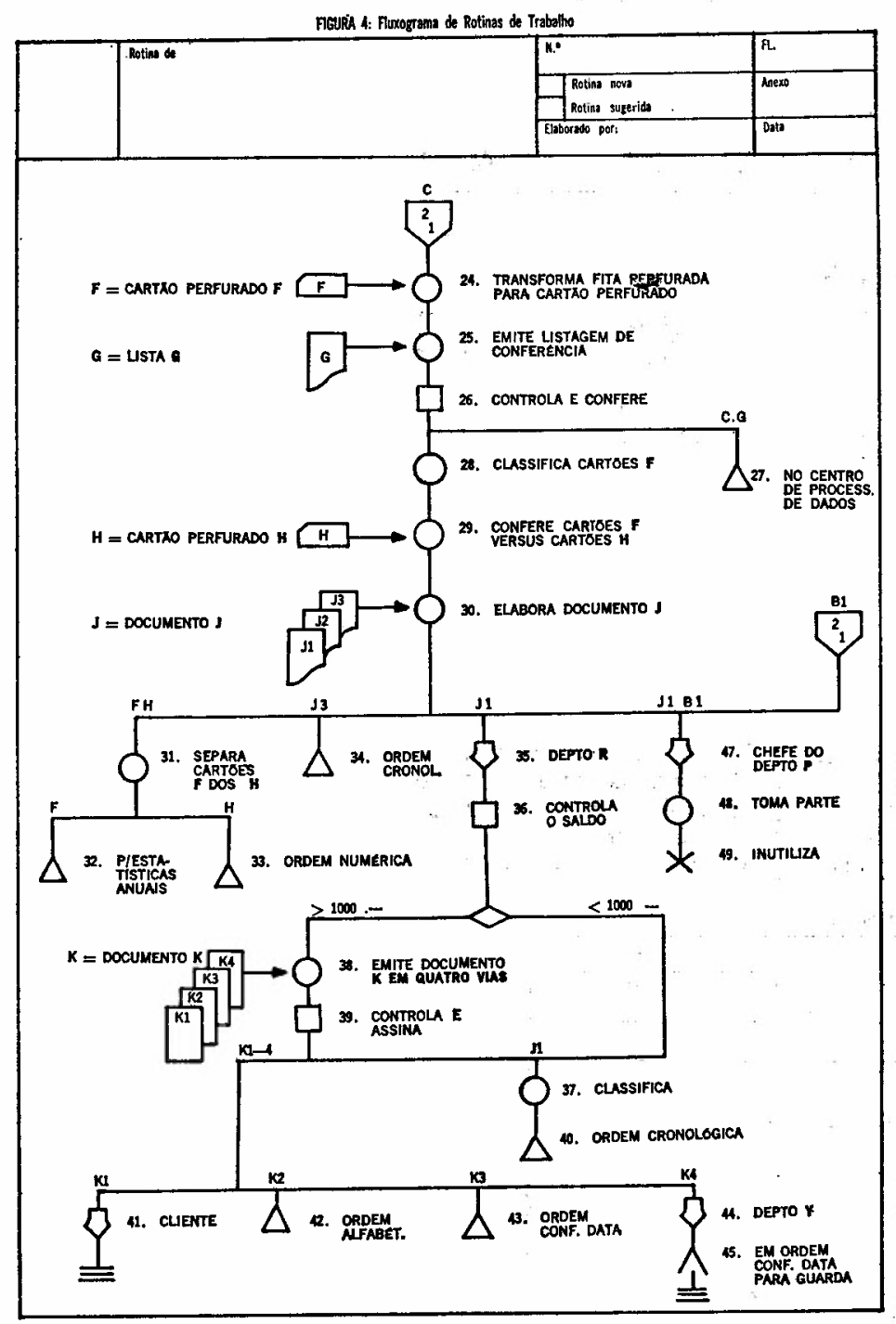

\subsection{Fluxograma de operaçōes}

O fluxograma de operações é estruturado de tal forma que a descrição deve ser orientada por documentos ou por eventos ou atividades. Por essa razão, o fluxograma de operações é particularmente necessário quando se tratar de descriçōes que tenham como objetivo a orientação daqueles que virão a operar com aquêles documentos ou com aquela rotina. O nível de detalhamento do fluxograma deve corresponder à sua finalidade.

O fluxograma de operações é confeccionado em formulário próprio, apresentado na figura 5, que tem a forma de uma tabela com várias colunas. A primeira coluna à esquerda destina-se ao lançamento do nome, do código ou do número do funcionário que executa a operaçăo ou, ainda, do nome ou código do setor responsável pela execução da mencionada operaçăo. A segunda e a terceira colunas destinam-se ao lançamento do número e de uma breve descrição da operação. Nas demais colunas indica-se, no cabeçalho, a denominação ou 0 código do documento ou do setor em foco, preenchendo-as para cada operação mencionada à esquerda (segunda e terceira colunas), com os símbolos básicos correspondentes. No caso em que se repitam, em dois ou mais documentos, ou vias de um mesmo documento, a mesma operação, na coluna correspondente ao documento básico, o símbolo de operação será substituído por um círculo menor completamente preenchido, e nas demais colunas, correspondentes aos outros documentos coloca-se 0 símbolo normal de operação. Tais símbolos devem ser interligados por uma linha contínua, conforme ilustrado pela figura 5.

Para operações que se realizem mediante informações provenientes de outro documento, ou que dependam de outro documento, os símbolos devem ser interligados por uma linha tracejada, conforme figura 5 . 


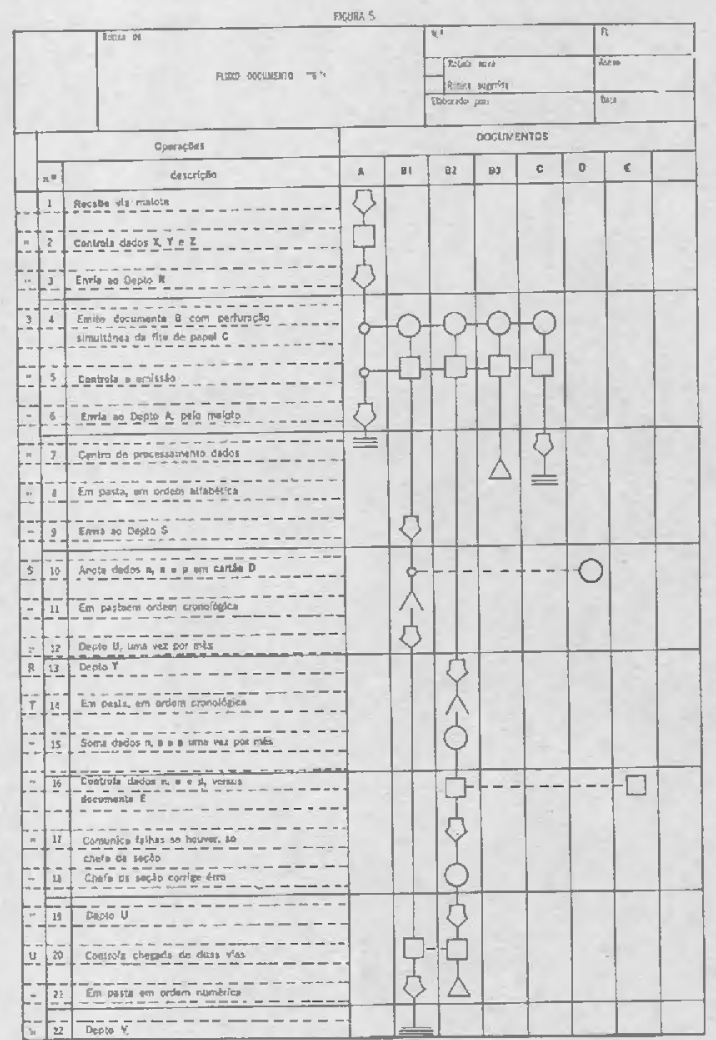

Sempre que o fluxograma de operaçōes fôr utilizado para descrever - fluxo de um trabalho a ser implantado, é interessante que o fluxograma apresentado pela figura 5 seja complementado por aquêle que é ilustrado pela figura 6 ,

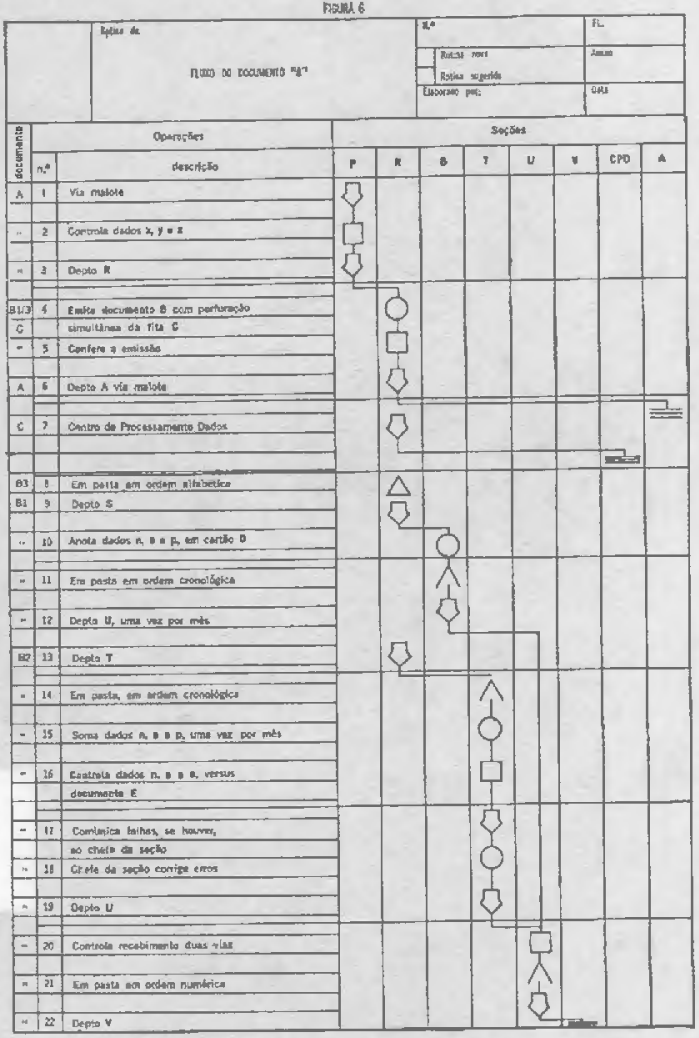

no qual é representado o fluxo do documento através dos diversos setores envolvidos.

Para maior facilidade de compreensão e de referências, é desejável que cada operação seja numerada separadamente.

Quando fôr desejável uma descrição das operações de forma mais abreviada, as palavras que se encontram sublinhadas nas figuras 5 e 6 poderăo ser omitidas.

A Comissāo Econômica para a América Latina - CEPAL edita publiçaçōes sôbre deserivolvimento econômico, agricultura, comércio, indústria, etc.., além das seguintẹ revistas:

Boletín Económico de América Latina

Boletín Estatistico de América Latina

Estudio Económico de América Latina

Para melhores informaçōes, escreva à

FUNDAÇĀO GETÚLIO VARGAS,

Serviço de Publicaçōes, Praia de Botafogo 188 ,

Caixa Postal 21.120, ZC-05, Rio de Joneiro, G8.
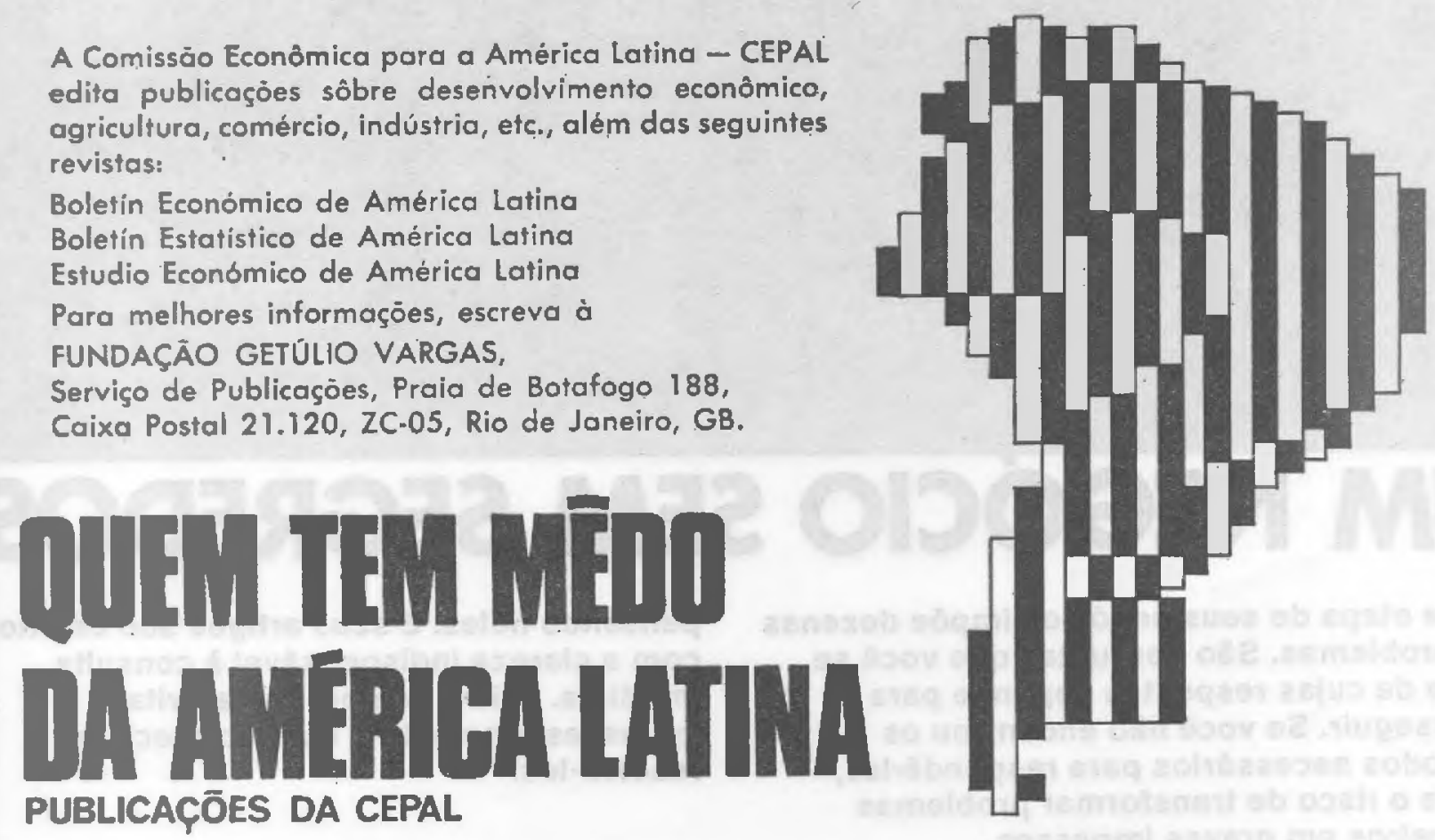